\title{
DEVELOPMENT AND TEST OF THE EQUIPMENT COMPLEX FOR MEASURING THE FLUID TEMPERATURE AND FLOW RATE
}

\author{
• • влов, • • ондр шов, • • ронин
}

P. L. Pavlova, P. M. Kondrashov, O. A. Tronin

лючевые слов : комплекс; оборудов ние для измерения; термоизмеритель; p сходжидкости;

д тиик темпер туры; измерение темпер туры; измерение р сход

Key words: complex; equipment for measurement; heat meter; fluid flow rate; temperature sensor; flow rate measurement

бзор и н лиз открытой литер туры по термоз щитному оборудов нию $[1,2,3]$ для нефтег зового комплекс пок з л отсутствие устройств, которые могли бы упр влять тепловыми процесс ми внутри скв жины во время ее строительств и эксплу т ции в $\mathrm{p}$ йон х с многолетнемерзлыми пород ми. д нной целью н к федре « шины и оборудов ние нефтяных и г зовых промыслов» институт нефти и г 3 ибирского федер льного университет $\mathrm{p}$ зр б тыв ется устройство н основе термоэлектрического эффект ельтье [5], н зв нное « кв жинным термоэлектрическим устройством» (рис. 1).

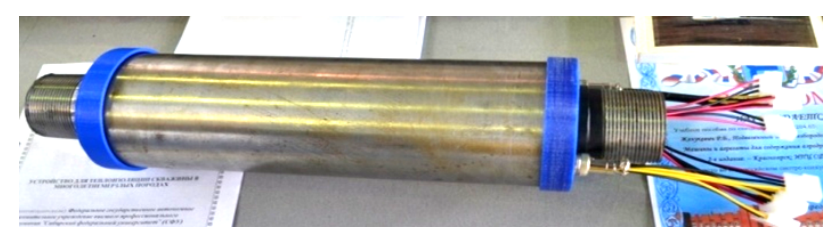

ис. 1. пытный л бор торный обр зец скв жинного термоэлектрического устройств

ля д льнейших эксперимент льных исследов ний термоэлектрического скв жинного устройств по р зр бот нной методике ре лизов н комплекс оборудов ния для измерения темпер туры и р сход жидкости. омплекс оборудов ния состоит из д тчиков - термоизмерителей, которые измеряют темпер туры р бочей жидкости, поверхности л бор торного обр зц и д тчик р сход жидкости. ля регистр ции темпер туры в шести точк х и р сход жидкости р зр бот но прогр ммное обеспечение. труктурн я схем комплекс оборудов ния для измерения темпер туры и р сход жидкости пок 3 н н рис. 2.

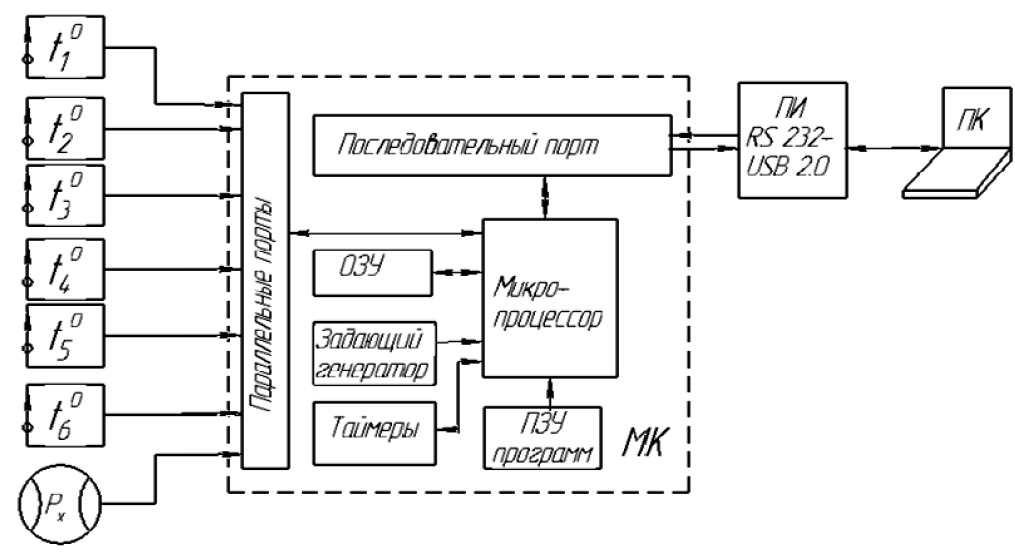

ис. 2. труктурн я схем комплекс оборудов ния для измерения темпер туры ир сход жидкости 
ермоизмеритель для измерения темпер туры р бочей жидкости состоит из корпус с метрической резьбой 3, г йки 4, д тчик DS18B20 5, провод 7, резиновой м нжеты 2 , колп чк 1 , внутренняя полость н полнен герметиком 6 (рис. 3,4 ), оборудов ние для измерения темпер турын поверхности л бор торного обр зц - хомутов для крепления и д тчиков темпер туры DS18B20 с провод ми. нное оборудов ние измеряет темпер туру в ди п зоне от -10 до $+85^{0}$ с погрешностью не более $\pm 0,5^{0}$.

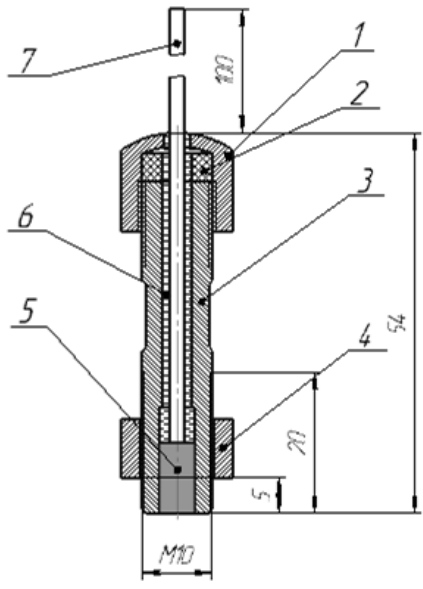

ис. 3. хем термоизмерителя для измерения темпер туры р бочей жидкости

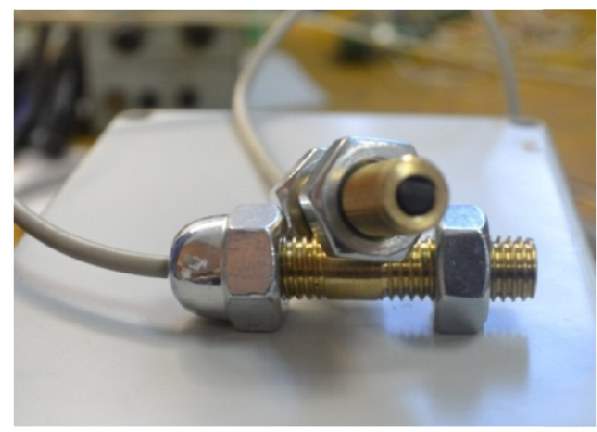

ис. 4. з зр бот нный термоизмеритель для измерения темпер туры р бочей жидкости

омплекс оборудов ния р бот ет следующим обр зом: цифровой код темпер туры и $\mathrm{p}$ сход жидкости от д тчиков $t_{1}^{0}, t_{2}^{0}, t_{3}^{0}, t_{4}^{0}, t_{5}^{0}, t_{6}^{0}$ и $P_{x}$ перед ется в микроконтроллер ( ), где происходит преобр зов ние полученных кодов темпер туры и р сход, перед ч их н преобр зов тель интерфейс RS232 в USB 2.0. ( ). езульт ты измерения д тчиков отобр ж ются н экр не персон льного компьютер ( ) в режиме рельного времени с помощью специ лизиров нного прогр ммного обеспечения с возможностью з писи в ф йл н жестком диске.

ункцион льные возможности прогр ммного обеспечения: вывод д нных темпер туры и р сход жидкости в цифровом и гр фическом виде н экр н монитор ; экспорт д нных в форм т Excel; з д ние периодичности измерения д нных; ввод коммент риев.

тчик DS18 20 имеет следующие основные х р ктеристики:

- обмен д нными по 1-Wire шине, то есть требуется только один конт кт для связи;

- ди п зон н пряжения пит ния сост вляет от 3 до 5,5 ;

- ди п зон измерения темпер туры от -10 до $+85^{0}$;

- погрешность измерения не более $\pm 0,5^{0}$;

- возможность пит ния н пряжением линии д нных при отсутствии внешнего источник н пряжения («П р зитное пит ние»).

льтр звуковой р сходомер - счетчик « непр-7» измеряет объемный р сход жидкости. основным техническим х р ктеристик м относятся:

- ди п зон темпер туры жидкости, р сход которой измеряется от 1 до $150{ }^{\circ}$;

- измерение р сход в безн порных трубопровод х и коллектор х производится в одном из трех ди п зонов скорости течения жидкости: 1 ди п зон - от 0,05 до 1,5 м/с; 2 ди п зон - от 0,3 до 3 м/с; 3 ди п зон - от 0,2 до 6 м/с.

омплекс можно использов ть для л бор торных исследов ний, где необходимо измерять темпер туру и р сход жидкости отдельно либо совместно, строить их гр фики 3 висимостей.

рис. 5 пок з но применение комплекс оборудов ния для измерения темпер туры н л бор торном обр зце скв жинного термоэлектрического устройств . 


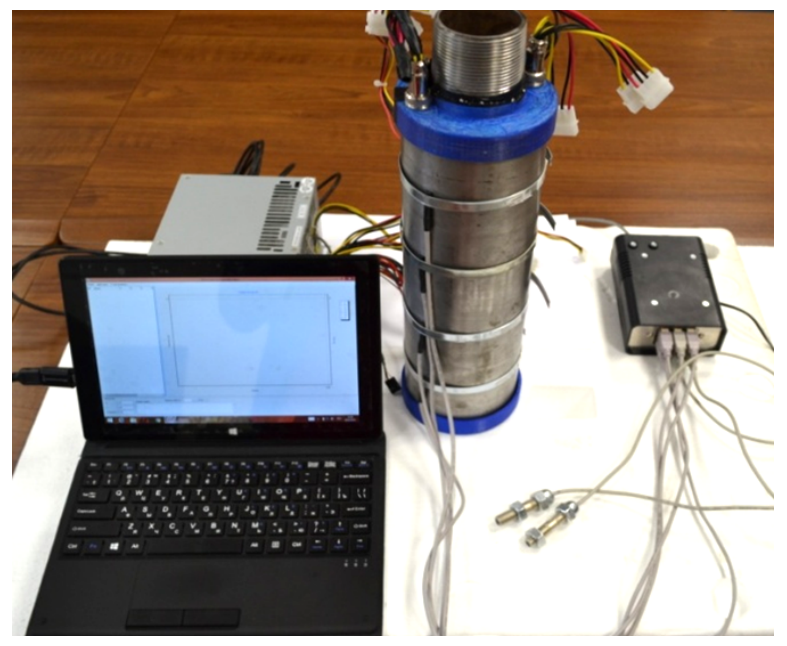

ис. 5. рименение комплекс оборудов ния для измерения темпер туры н

л бор торном обр зце скв жиинного

термоэлектрического устройств

основным преимуществ м д нного комплекс оборудов ния для измерения темпер туры и р сход жидкости относятся:

- простот и эргономичность:

- интуитивное поним ние интерфейс прогр ммного обеспечения;

- применение д тчиков, которые широко используются в промышленности.

ыполнено в ходе ре лиз ции гр нт конкурс «. . . . » по договору № 2308 1/2014 от 19.06.2014 « зр ботк устройств для теплоизоляции скв жиин в р йон хс многолетнемерзлыми пород ми»

борудов ние для измерения темпер туры получены из гр нт « ентр продвижения молодежных проектов «

писок литер турь

1. ыков . ., обылев . . ермоз щит конструкций скв жин в мерзлых пород х: учеб. пособие. - хт : 2007. $-131 \mathrm{c}$.

2. влов . ., олосов . ., ондр шов . ., еньков . . зр ботк опытного обр зц устройств для термост билиз ции мерзлой породы // ефтег зовое дело. - ф : $\quad$ - 2014- № 6 - .679-697.

3. влов . ., ондр шов . . зр ботк м тем тической модели р спределения темпер туры от скв жинного термоэлектрического устройств // борудов ние и технологии для нефтег зового комплекс . - . 2016, - № 1. - . 40-44

4. ернов . усское опис ние р боты с д тчиком темпер туры DS18B20. - кр ин, непропетровск: гетекс, 2009. - 33 с

5. уководство по эксплу т ции « сходомер - счетчик ультр звуковой « непр -7», 2005. - 94 с.

ведения об втор $x$

влов р сковья еонидовн, спир нт $\kappa$ федры « шины и оборудов ние нефтяных $и$ 2 зовых промыслов» институт нефти и 23 ибирский федер льный университет, г. р сноярск, тел. 8(983)2944865, e-mail: praskovya2611@yandex.ru

ондр шов етр их йлович, к. иент, з ведующий к федрой « шины и оборудов ние нефтяных и г зовых промыслов» институm нефти иг з, ибирский федер льный универcuтет, г. p сноярск, ел: 8(913)5071730, е-mail: p_kondrashov@mail.ru

ронин лег лекс ндрович, к. т. н., доцент, институт инженерной электроники и р диоэлектроники, ибирский федер льный универси тет, г. р сноярск, тел. 8(906)9129283, е-таil: toa12@yandex.ru

\section{Information about the authors}

Pavlova P. L., postgraduate of the chair «Machines and equipment for oil and gas fields», The Institute of oil and gas, Siberian Federal University, Krasnoyarsk, phone: 8(983)2944865, e-mail: praskovya2611@yandex.ru

Kondrashov P. M., Candidate of Science in Engineering, associate professor of the chair «Machines and equipment for oil and gas fields», The Institute of oil and gas, Siberian Federal University, Krasnoyarsk, phone: 8(913)5071730, e-mail: p_kondrashov@mail.ru

Tronin O. A., Candidate of Science in Engineering, associate professor of the Institute of engineering electronics and radio electronics, Siberian Federal University, Krasnoyarsk, phone: 8(906)9129283, e-mail:toa12@yandex.ru 